\title{
A Cytohistological Correlation in Ovarian Tumours
}

\author{
Dr. Chhanda Das ${ }^{1}$, Dr. Madhumita Mukhopadhyay ${ }^{1}$, Dr. Ashis Kumar Saha ${ }^{2}$, \\ Dr. Moumita Sengupta ${ }^{1}$, Dr. Goutam Dhar ${ }^{3}$ \\ ${ }^{I}$ (Department of Pathology, IPGME\&R, Kolkata, India.) \\ ${ }^{2}$ (Department of Surgery, B.S.Medical College, Bankura, India) \\ ${ }^{3}$ (Department of Community Medicine, N. R. S. Medical College, Kolkata, India)
}

\begin{abstract}
The present study was conducted to assess whether imprint cytology can help in rapid diagnosis of ovarian neoplasm and thus facilitate individualized treatment. Aims of our study were to establish the validity and reliability of Imprint cytology in intraoperative diagnosis of ovarian tumour and to compare the significance of cytological diagnosis with histopathological report. Ours is an Institution base prospective study designed on 50 cases of clinically and radiologically diagnosed ovarian tumour at the Dept of pathology $I P G M E \& R$, Kolkata which is a tertiary care referral hospital. Imprint smears were made intraoperatively from fresh samples and stained with M.G.G. stain for air dried smears and Papanicolaou stain for alcohol fixed smears. Stained smear was examined under light microscope and cytological findings were noted. Tissue for histopathological study was obtained in the form of post operative material. The previous cytological findings were compared with subsequent histopathology report. Out of total 50 cases, 32(64\%) was epithelial tumours and 18(36\%) non-epithelial tumour cases. Age group varied from 5 to 62 years. Overall sensitivity in our study to diagnose benign and malignant ovarian tumours by imprint cytology is $94 \%$ and the specificity is $74 \%$ with positive and negative predictive value of 63\% and $96 \%$ respectively. Diagnostic accuracy was $78 \%$ with high statistical significance $(p<0.001)$. Hence we conclude that imprint cytology is a less expensive, simple, fast and reliable method for diagnosis of various ovarian neoplasms.
\end{abstract}

Keywords: Ovarian Tumour, Imprint Cytology, flow-cytometry

\section{Introduction}

Ovarian neoplasm is a heterogeneous group of benign and malignant tumours of epithelial, stromal and germ cell origin. Ovarian carcinoma account for $3 \%$ of all carcinomas of female and $5^{\text {th }}$ most common cause of death due to carcinoma in women in United States ${ }^{[1]}$. Incidence of ovarian carcinoma in India was $5.6 \%$ in the year $2004^{[2]}$. Most of the ovarian carcinomas are usually detected when they have spread beyond the ovary. Ovarian tumours cannot be easily distinguished from one another on the basis of their clinical and gross characteristics alone. Therefore, cytological interpretation of ovarian neoplasm is both interesting and challenging ${ }^{[3]}$. Fine Needle Aspiration Cytology as a preoperative investigation has been discouraged, because deep location makes it relatively inaccessible for aspiration without image guidance. Further approach is controversial from safety point of view due to possibility of needle tract seeding and dissemination ${ }^{[4[5][6]}$. But intraoperative imprint cytology will provide rapid diagnosis (within 20 minutes) without the fear of dissemination. Rapid intraoperative diagnosis of the nature of the ovarian tumour in young woman avoids unnecessary removal of the contra lateral ovary and helps in preservation of fertility. It can also be used for staging of malignancy, for postoperative follow up and for recurrence ${ }^{[7]}$. Materials obtained from imprint can be used for flow-cytometry and cytogenetic studies. In spite of all these advantages imprint cytology has been underutilized as a modality for primary diagnosis of ovarian carcinoma. We undertook this study to find out the accuracy of imprint cytology as intraoperative diagnostic modality in case of ovarian tumours by cytohistological correlation.

\section{Materials And Methods}

This prospective study was carried out in the Department of Pathology of our hospital in collaboration with Department of Gynaecology from October 2010 to September 2012. Institutional ethical committee approval was taken. Fifty consecutive patients attending Gynaecology and Obstetrics OPD \& indoor and diagnosed as cases ovarian tumour clinically \& radiologically (USG) was selected. After taking valid consent from the patients, a detailed history was taken and clinical examination was done preoperatively. Intraoperative imprint smears were taken from fresh ovarian tissue on four alcohols clean and grease free plain slides after blotting excess blood from the cut surface. Two slides were air dried and stained with May-Grunewald-Giemsa (M.G.G). Two slides were fixed in 95\% methyl alcohol and stained with Papanicolaou stain. Stained slides were examined under light microscope and findings were recorded depending on the cellularity, arrangement, morphology and background. The resected masses were sent for histopathological examination. After proper 
processing of the representative sections, slides were stained with Haematoxylin and Eosin stain. Histopathological categorization was done according to WHO classification after examining the slides under light microscope. Results of imprint cytology and histopathology were compared.

\section{Results}

Total number of cases studied in our study was fifty which include $32(64 \%)$ epithelial tumours and $18(36 \%)$ non-epithelial tumours. All cases were further categorized into benign (16cases; $32 \%$ ), borderline (1case; $2 \%$ ) and malignant (33cases; 66\%).

According to the histopathological interpretation, serous tumours were found as the most common diagnosis with prevalence of $34 \%$ (17 cases) followed by germ cell tumour (24\%) and mucinous tumour (14\%).

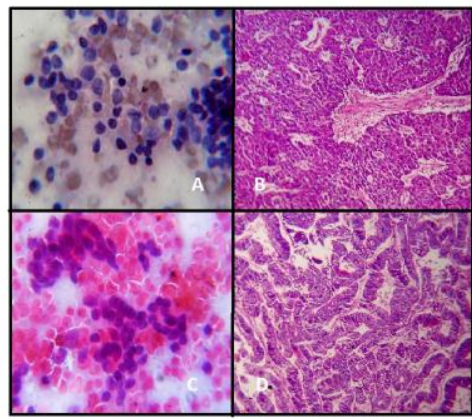

Figure 1: (A) Imprint cytology of granulosa cell tumour PAP x1000, (B) Histology of granulosa cell tumour $\mathrm{H} \& \mathrm{E}$ X100, (C) Imprint cytology of endometrioid carcinoma PAP X1000, (D) Histology of endometrioid carcinoma H\&E X 100

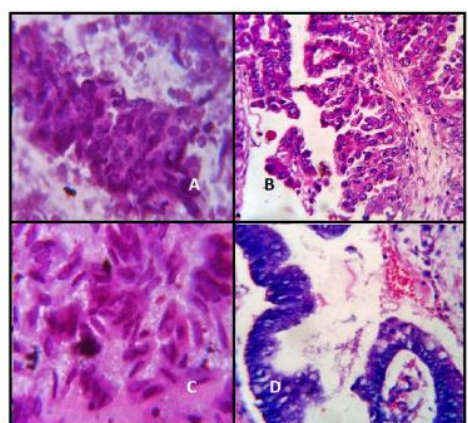

Figure 2: (A) Imprint cytology of serous papillary cystadenocarcinoma PAP x1000, (B) Histology of serous papillary cystadenocarcinoma H\&E X400, (C) Imprint cytology of mucinous cystadenocarcinoma PAP X1000, (D) Histology of mucinous cystadenocarcinoma H\&E X400

Patients were found to be aged between 5 to 62 years and majority belongs to age group of 21-30 yrs. Only one case of ovarian tumour was noted at the age group of below 10 years (immature teratoma).

As per as the laterality of the tumour is concerned, most of the benign tumours were unilateral and bilateral presentation was seen in Metastatic adenocarcinoma and serous papillary cystadenocarcinoma.

Out of the 32 epithelial tumours, $18(36 \%)$ cases were cystic, 30(60\%) cases were mixed consistency and 2(4\%) cases were solid type (metastatic adenocarcinoma). Among the 30 mixed type cases 15 cases were non epithelial tumours

Cytological findings obtained from imprint smears [TABLE-1] were compared with the histopathological reports. Out of the total 50 cases, good correlation was observed in 39 cases and 11 cases were not correlated. Cases of granulosa cell tumour (3), dysgerminoma (2), metastatic adenocarcinoma (3) and endometriotic cyst (5) were correctly diagnosed by imprint cytology. All 4 cases of immature cystic teratoma were wrongly interpreted by imprint cytology.

As per as the mucinous tumours were concerned, 4 out of the 5 cases of mucinous cystadenocarcinoma were wrongly diagnosed as mucinous cystadenoma by and 1 out of 2 cases of mucinous cystadenoma was wrongly diagnosed as mucinous cystadenocarcinoma by imprint cytology.

All cases of the serous papillary cystadenoma (11) were correctly diagnosed by imprint cytology. Only one borderline case of serous tumour was wrongly diagnosed as benign tumour.

2 cases of yolk sac tumours were wrongly identified by imprint cytology as anaplastic carcinoma. Cytohistological correlation is elaborated in [TABLE-2]. 
Table-1 showing cytomorphological findings of ovarian tumours

\begin{tabular}{|c|c|}
\hline DIAGNOSIS & CYTOLOGICAL FINDINGS \\
\hline Serous cystadenoma & Monomorphic cells in sheet with maintained $\mathrm{N}: \mathrm{C}$ ratio \\
\hline $\begin{array}{c}\text { Papillary serous } \\
\text { cystadenocarcinoma }\end{array}$ & $\begin{array}{l}\text { Papillary tissue fragments of malignant glandular cells, scanty cytoplasm, and } \\
\text { high N/C ratio }\end{array}$ \\
\hline Mucinous cystadenoma & Mucin filled columnar cells in cohesive cluster and maintained $\mathrm{N}: \mathrm{C}$ ratio \\
\hline $\begin{array}{c}\text { Mucinous } \\
\text { cystadenocarcinoma }\end{array}$ & $\begin{array}{c}\text { Mucin filled cells, complex branching, nuclear pleomorphism, } \\
\text { hyperchromasia and high N:C ratio }\end{array}$ \\
\hline Endometrioid carcinoma & Loose clusters of malignant glandular cells with acinar pattern \\
\hline Dysgerminoma & $\begin{array}{c}\text { Poorly cohesive malignant cells, fragile cytoplasm, vesicular nuclei with } \\
\text { prominent nucleoli, and few lymphocytes }\end{array}$ \\
\hline Granulosa cell tumour & $\begin{array}{l}\begin{array}{c}\text { Clusters of uniform round nuclei \& granular chromatin, micro follicle, } \\
\text { grooved nuclei }\end{array}\end{array}$ \\
\hline Anaplastic carcinoma & Highly pleomorphic cells \\
\hline Mature teratoma & Squamous cells \\
\hline Endometriotic cyst & $\begin{array}{l}\text { Sheets of columnar epithelial cells, many haemosiderin containing } \\
\text { macrophages. }\end{array}$ \\
\hline atic adeno & $r$ pattern in a necrotic $b$ \\
\hline
\end{tabular}

Table: 2 Table Showing Cytohistological Correlation:

\begin{tabular}{|c|c|c|c|c|c|}
\hline & & Imprint cytology & $\begin{array}{l}\text { no of } \\
\text { cases }\end{array}$ & Histopathology & $\begin{array}{l}\text { no of } \\
\text { cases }\end{array}$ \\
\hline \multirow{6}{*}{ 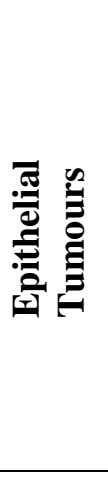 } & \multirow{3}{*}{$\cdot \frac{\text {.0 }}{\vec{E}}$} & Benign serous cystadenoma & 6 & Benign serous cystadenoma & 5 \\
\hline & & Mucinous cystadenoma & 5 & Mucinous cystadenoma & 2 \\
\hline & & Endometriotic cyst & 5 & Endometriotic cyst & 5 \\
\hline & \multirow{3}{*}{ 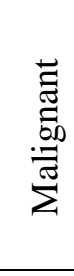 } & $\begin{array}{l}\text { Serous papillary } \\
\text { cystadenocarcinoma }\end{array}$ & 11 & $\begin{array}{l}\text { Serous papillary } \\
\text { cystadenocarcinoma }\end{array}$ & 11 \\
\hline & & Mucinous cystadenocarcinoma & 2 & Mucinous cystadenocarcinoma & 5 \\
\hline & & Endometrioid carcinoma & 3 & $\begin{array}{l}\text { Endometrioid carcinoma } \\
\text { Borderline serous } \\
\text { cystadenocarcinoma }\end{array}$ & $\begin{array}{l}3 \\
1 \\
\end{array}$ \\
\hline \multirow{6}{*}{ 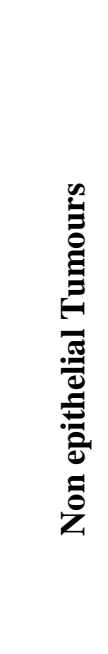 } & 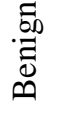 & Mature teratoma & 8 & Mature teratoma & 4 \\
\hline & \multirow{4}{*}{ 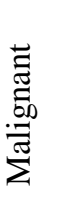 } & & & Immature teratoma & 4 \\
\hline & & Anaplastic carcinoma & 2 & Yolk sac tumour & 2 \\
\hline & & Dysgerminoma & 2 & Dysgerminoma & 2 \\
\hline & & Granulosa cell tumour & 3 & Granulosa cell tumour & 3 \\
\hline & 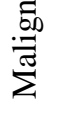 & Metastatic adenocarcinoma & 3 & Metastatic adenocarcinoma & 3 \\
\hline
\end{tabular}

Correlated -39

Non correlated -11 


\section{Discussion}

In the areas of the world where access to intraoperative histological diagnosis is limited, imprint cytology is probably the only means of rapid intraoperative consultation. The ability to deliver an immediate diagnosis makes imprint cytology an important part of management at places where frozen section facility is not available, which needs an advance setup ${ }^{[8]}$. The advantage of cytological examination is the avoidance of artefact produced by freezing and sectioning technique of frozen section ${ }^{[9]}$. Imprint cytology gives better cellular morphology.

We had done intraoperative imprint cytological examination in 50 cases fulfilling the inclusion criteria and histological follow up was carried out in all cases. In present study the most common type of epithelial tumour was serous tumour 17/50(34\%). Pravakar and Maingi ${ }^{[10]}$ also found it to be the most common one but their incidence was $32.7 \%$. Largest tumour seen in our study was mucinous cystadenocarcinoma. Kar Tushar et $\mathrm{al}^{[7]}$ also studied mucinous cystadenocarcinoma in their study as the largest tumour.

Benign cystic teratoma comprised $5(10 \%)$ cases. All are cystic, unilateral, contained serous fluid, age group between 11-40 years, as has been found by Fox and Well ${ }^{111}$. Serous cystadenocarcinoma occurred a decade later than the benign neoplasm. The benign mucinous neoplasms were predominant in 11 to 30 years and malignant mucinous neoplasms were most commonly found in 41 to 50 years age group. Granulosa cell tumour was common in the age group of 41 to 50 years which was similar to the observation made by Young et al ${ }^{[12]}$ i.e. $>45$ years.

Malignant serous tumours accounted for 11(22\%). Ramchandran et al ${ }^{[13]}$ found a lower incidence of 7.09\%. Imprint cytology showed $100 \%$ diagnostic accuracy. One borderline serous tumour was wrongly diagnosed as benign serous tumour because the reliability of imprint cytology was questionable on borderline tumour. In absence of complex branching, nuclear pleomorphism and hyperchromasia, the overall morphology of cells closely resembles that of a benign serous tumour. Also it is extremely difficult to separate epithelial tumours of low malignant potential from well differentiated carcinoma ${ }^{[14][15]}$. Hence this is the limitation of diagnosis by touch imprint and hence histopathology is considered the gold standard for diagnosis. However, considering its rapidity and cost effectiveness touch imprint is yet practicable.

There are few studies regarding imprint cytology of ovarian neoplasm. In our study sensitivity was $94 \%$, specificity $74 \%$, diagnostic accuracy $78 \%$. In the study of imprint cytology of ovarian neoplasms done by Kar Tushar et al ${ }^{[7]}$ (2005), the sensitivity and specificity were $93 \%$ and $92 \%$ respectively. Nadji et al. (1979) ${ }^{[16]}$ had a sensitivity and specificity of $96.4 \%$ and $92 \%$ respectively in their study on fine needle aspiration cytology of ovarian neoplasms. The overall diagnostic accuracy of scrape cytology was satisfactory with $92 \%$ of cases correlating with histopathological diagnosis according to Shalinee et al (2009) with specificity of $96.4 \%$ and $92 \%$ respectively in their study on fine needle aspiration cytology of ovarian neoplasms ${ }^{[17]}$. Dey Soumit et al had sensitivity $96.2 \%$, specificity $75 \%$, and diagnostic accuracy $83.3 \%$ compared to our study4. Mikami M. ${ }^{[18]}$ et al studied sclerosing stromal tumour (SST) of ovary for imprint cytology. Considering SST most commonly occurs in young woman requiring conservative treatment, imprint cytology seems to have potential diagnostic significance.

Nagai et al ${ }^{[19]}$ studied on 354 samples, the role of the imprint cytology as the intraoperative pathological consultation for ovarian epithelial tumours. Final pathological diagnosis was made according to WHO classification. The accuracies to differentiate benign from malignant were $87.1 \%$ and $83.6 \%$ respectively.

Imprint cytology does not alter the quality of biopsy specimen ${ }^{[20]}$. Materials obtained from imprint can be used for flow cytometry and cytogenetic studies. In a case of large ovarian tumours sampling various sites increases the cellular yield which overcomes the limitation resulting from scarce no of tissue samples processed and examined by frozen section ${ }^{[21]}$.

\section{Conclusions}

Imprint cytology is a less expensive, simple, fast and reliable method for diagnosis of various ovarian neoplasms.

\section{References}

[1] Ellenson LH, Pirog EC, The female genital tract. In:Kumar V, Abbas AK, Fausto N, Aster JC. Robbins and Cotran Pathological Basis of Disease $8^{\text {th }}$ ed. Pennsylvania: Elsevier Inc; 2010: p. 1040.

[2] M. Krishnan Nair, Cherian Verghese, R. Swaminathan. Cancer: Current scenario, intervention strategies and projections for 2015

[3] Bonfiglio TA, Yener S E. Gynaecologic Cytology Philadelphia, Lippincott- Raven. 1997:157-64.

[4] Dey Soumit. Role of Intraoperative Imprint cytology in diagnosis of suspected ovarian neoplasms, Asian Pacific J. of Cancer Prev. 2010;11:1389-91.

[5] Hajdu SI, Melamed MR. Limitations in aspiration cytology in the diagnosis of primary neoplasms, Acta Cytol, 1984; $28: 337-45$.

[6] Uguz A, Ersoz C, Bolat F. Fine needle aspiration cytology of ovarian lesions, Acta Cytol, 2005; 49:144-8.

[7] Kar Tushar, Kar A, Mohapatra PC. Intraoperative cytology of ovarian tumours, J Obstetrics and Gynaecol India, 2005;55, 4:345-9.

[8] Michael CW, Lawrence WD, Bedrossian CW. Intraoperative consultation in ovarian lesions: a comparison between cytology and frozen section, Diagn Cytopathol, 1996;15: 387-94. 
[9] Mair S, Lash LS, Suskin D, Mendelsohn G: Intraoperative surgical specimen evaluation: frozen section analysis, cytologic examination or both? Am J. Clin Pathol 1991;96:8-14.

[10] Pravakar BRE, Maingi K. Ovarian tumours- Prevalence in Punjab- A study of 636 cases, Ind J Pathol Microbiol.1989;32:276-81.

[11] Fox H, Wells M. Heins and Taylor Obstetrics and Gynaecological Pathology. $5^{\text {th }}$ ed. London, UK: Charchill Livingstone; 2003, p. 585-912.

[12] Young RH, Oliva E, Scully RE. Luteinized adult granulosa cell tumours of the ovary: a report of four cases, Int J Gynecol Pathol 1994:13:302-310.

[13] Ramachandran G, Hiralal KR,Chhinnamma KK. Ovarian neoplasm- A study of 903 cases, J Obstet Gynecol India 1972; 22:309-15.

[14] Ganjei P, Nadji M. Aspiration cytology of ovarian neoplasms. A review, Acta Cytol 1984;28:329.

[15] Nadji M. Aspiration cytology in diagnosis and assessment of ovarian neoplasms. In: Roth LM, Czernobilsky B (eds). Tumours and tumour like conditions of the ovary. New York. Churchill Livingstone, 1985:153.

[16] Nadji M, Greening SE, Sevin BU. Fine needle aspiration cytology in gynaecologic oncology ii, morphologic aspects, Acta Cytol $1979 ; 23: 380-8$.

[17] Shalinee R, Sadiya N, Leena DJ. Role of scrape cytology in ovarian neoplasms, J. Cytol, 2009; 26:26-9.

[18] Mikami M. Tumour imprint cytology sclerosing stromal tumour of ovary, Diagnostic Cytopath 2003;28:54-57.

[19] Nagai Y, Tnanaka N, Horiuci F, Ohki S, Sekiya S: Diagnostic accuracy of intraoperative cytology in ovarian epithelial tumour, Int J Gynaecol Obstet, 2001; 72:159-164.

[20] Misra SP, Misra V, Dwivedi M. Diagnosing H.Pylori by imprint cytology: can the same biopsy specimen be used for histology? Diagn Cytopathol 1998;18:330-2.

[21] Carmen AS, Adela S, Silvia M, Alicia F, Griselle G, Carmen R A. Contribution of intraoperative cytology to the diagnosis of ovarian lesions, Acta Cytologica 2011;55:85-91. 